\title{
2.5D Flexible Wind Sensor Using Differential Plate Capacitors
}

\author{
Yu Wan (1) and Zhenxiang Yi * \\ Key Laboratory of MEMS of the Ministry of Education, Southeast University, Nanjing 210096, China; \\ 220191417@seu.edu.cn \\ * Correspondence: xp@seu.edu.cn
}

\section{check for} updates

Citation: Wan, Y.; Yi, Z. 2.5D Flexible Wind Sensor Using Differential Plate Capacitors. Sensors 2021, 21, 3101. https://doi.org/10.3390/s21093101

Academic Editor: Yolanda Vidal

Received: 24 March 2021

Accepted: 26 April 2021

Published: 29 April 2021

Publisher's Note: MDPI stays neutral with regard to jurisdictional claims in published maps and institutional affiliations.

\begin{abstract}
In this paper, a novel 2.5-dimensional (2.5D) flexible wind sensor is proposed based on four differential plate capacitors. This design consists of a windward pillar, two electrode layers, and a support layer, which are all made of polydimethylsiloxane (PDMS) with different Young's moduli. A $2 \mathrm{~mm} \times 2 \mathrm{~mm}$ copper electrode array is located on each electrode layer, forming four parallel plate capacitors as the sensitive elements. The wind in the xy-plane tilts the windward pillar, decreasing two capacitances on the windward side and increasing two capacitances on the leeward side. The wind in the $z$-axis depresses the windward pillar, resulting in an increase of all four capacitances. Experiments demonstrate that this sensor can measure the wind speed up to $23.9 \mathrm{~m} / \mathrm{s}$ and the wind direction over the full $360^{\circ}$ range of the xy-plane. The sensitivities of wind speed are close to $4 \mathrm{fF} \cdot \mathrm{m}^{-1} \cdot \mathrm{s}$ and $3 \mathrm{fF} \cdot \mathrm{m}^{-1} \cdot \mathrm{s}$ in the $\mathrm{xy}$-plane and $z$-axis, respectively.
\end{abstract}

Keywords: wind sensor; flexible; 2.5D; capacitors

\section{Introduction}

As a natural phenomenon, wind has a significant impact on our lives. The measurement of wind speed and direction plays a very important role in many fields, such as meteorological detection, transportation, agricultural production, and aerospace. According to the measurement principle, anemometers can be divided into four categories: mechanical anemometers, thermal anemometers, sonic anemometers, and pressure anemometers. The mechanical anemometer has been in use for more than 150 years [1]. It has several advantages, including a simple structure, low production cost, and a strong anti-interference ability, but it cannot meet people's needs for portable devices due to its large size. Especially after the emergence of MEMS technology, the thermal anemometer began to attract the attention of researchers [2-9]. It has the advantages of miniaturization, high accuracy, and high sensitivity. However, the thermal anemometer requires high power consumption to form a temperature field. In this regard, the pressure anemometer uses some passive devices, such as resistors, inductors, and capacitors, to convert wind information into electrical signals, achieving extremely low power consumption [10-17]. However, in practice, the sensitive elements are directly exposed to the air and are susceptible to the interference of dust particles, leading to a decline in reliability. In addition, all of the anemometers above can only detect one-dimensional (1D) or two-dimensional (2D) wind speeds and direction measurements. However, in addition to the xy-plane, wind speed information in the $z$-axis is also needed in some areas, including unmanned aerial vehicle and indoor wind control systems. At present, the sonic anemometer is usually used for three-dimensional (3D) wind measurement, but it is sensitive to temperature changes, which can affect the measurement of the travel times along the sonic paths [1]. Moreover, it is expensive and difficult to miniaturize for use in portable devices.

Recently, flexible electronic devices have emerged [18,19]. The flexible material is deformed by external force, which can be characterized by capacitance variation. Therefore, in this paper, a novel flexible wind sensor based on differential plate capacitors is proposed. The sensor can measure the wind in the xy-plane and the negative $z$-axis and is described as 
a 2.5D (xy-plane and half of the $z$-axis) wind sensor due to the lack of the wind information in the positive $z$-axis. The electrodes of the capacitors are embedded in the substrate to avoid interference from the external environment directly, which can improve the reliability and lifespan of the device. Moreover, the wind speed sensor has the advantages of simple a fabrication process and no energy consumption. It is also worth mentioning that the sensitivity of the sensor can be improved by using four differential capacitors.

\section{Design and Simulation}

\subsection{Design and Principle}

The differential capacitive wind sensor proposed in this paper, as shown in Figure 1, consists of four polydimethylsiloxane (PDMS) layers, including a windward pillar, an upper electrode layer, a support layer, and a lower electrode layer. Among them, the radius and the thickness of the windward pillar are both designed to be $10 \mathrm{~mm}$. The dimensions of the other layers are all about $40 \mathrm{~mm} \times 40 \mathrm{~mm} \times 3 \mathrm{~mm}$. In particular, there is a micropillar with a radius of $3 \mathrm{~mm}$ in the center of the support layer, forming a lever structure with the windward pillar, which plays an important role in the measurement of wind speed and direction.
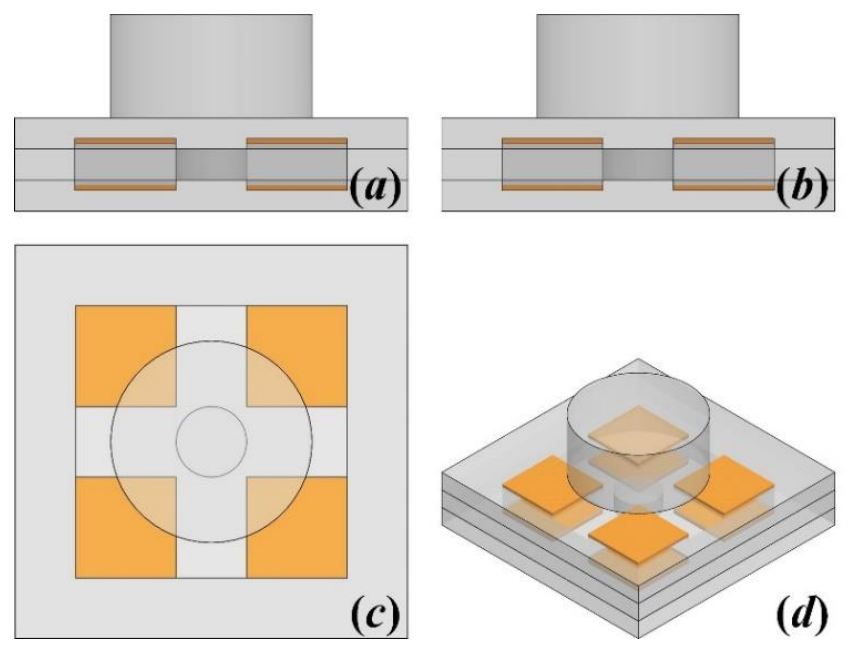
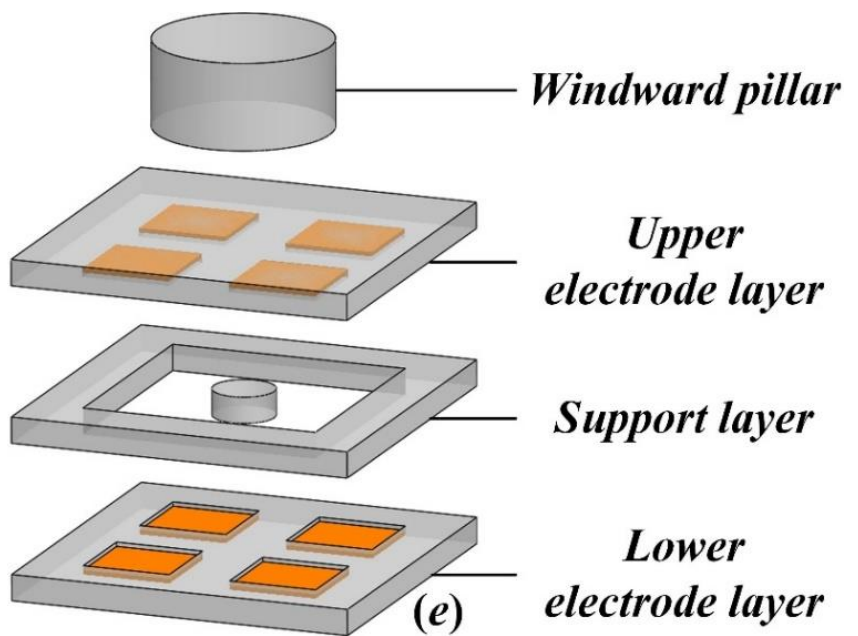

Support layer

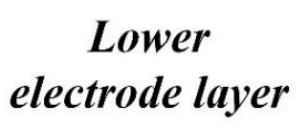

Figure 1. Schematic diagram of the proposed flexible wind sensor: (a) main view, (b) left view, (c) top view, (d) isometric view, and (e) hierarchical structure view.

There are 4 electrodes on each of the upper and lower electrode layers with a size of $10 \mathrm{~mm} \times 10 \mathrm{~mm}$, distributed in a $2 \times 2$ array. As shown in Figure 2, every two opposing electrodes (such as electrode 1 and electrode 5) form a parallel plate capacitor, so the sensor contains a $2 \times 2$ capacitor array. The capacitance value $C$ of the parallel plate capacitor is defined by:

$$
C=\frac{\varepsilon S}{d}
$$

where $\varepsilon$ is the dielectric constant of the medium between the upper and lower electrodes, $S$ is the area of the upper and lower electrodes facing each other, and $d$ is the distance between the upper and lower electrodes. In Equation (1), fringing field capacitance is not considered. In this paper, $\varepsilon$ and $S$ are fixed, while $\mathrm{d}$ changes with the deformation of the upper electrode layer caused by the wind. Therefore, the speed and direction of the wind can be measured through the changes of the four differential capacitances.

Table 1 illustrates the measurement principle along the $x, y$, and $z$ axes, respectively. On the $x$-axis, when the wind speed $v>0$, the windward column tilts toward the positive $x$-axis. As a result, $\mathrm{d} 1$ and $\mathrm{d} 2$ increase, while $\mathrm{d} 3$ and $\mathrm{d} 4$ decrease, leading to a decrease in $C_{1}, C_{2}$ and an increase in $C_{3}, C_{4}$. Consequently, the wind speed can be extracted by the four capacitances measurements. Similarly, for the condition of $v<0, C_{1}$ and $C_{2}$ increase 
while $C_{3}$ and $C_{4}$ decrease. The measurement principle on the $y$-axis is similar to that on the $x$-axis. If the wind blows the sensor from a certain angle to $x$-axis in the xy-plane, four capacitances vary with the wind direction according to the sine (or cosine) relationship.

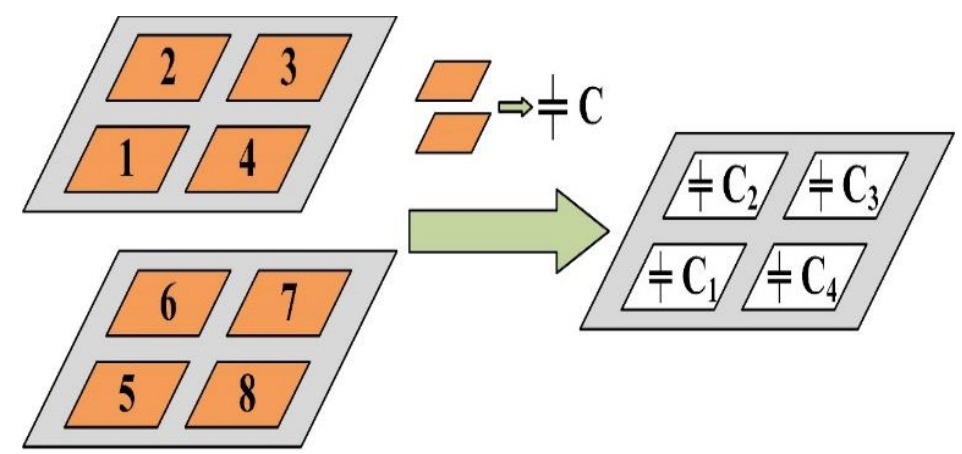

Figure 2. Schematic diagram of the four parallel plate capacitors.

Table 1. Measurement principle along different axes.

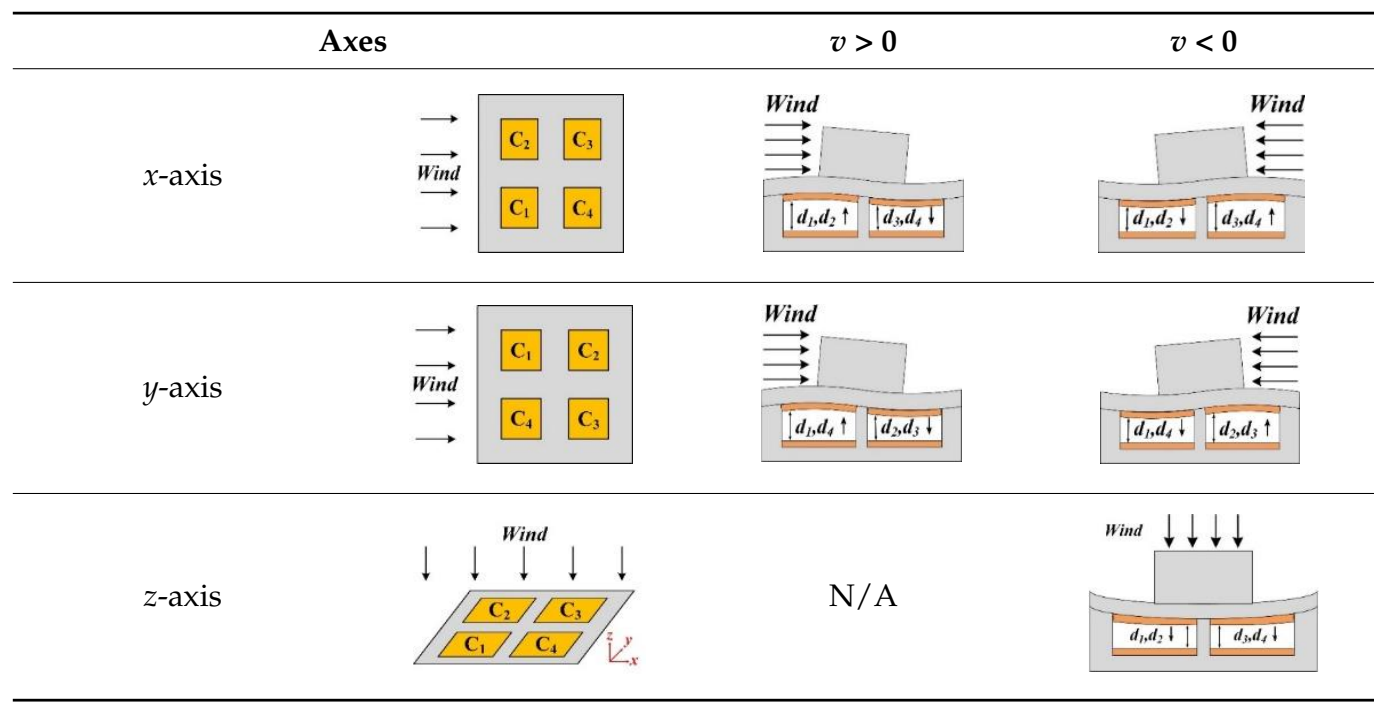

For this proposed 2.5D wind sensor, in the $z$-axis, when the wind speed $v<0$, the windward pillar and the upper electrode layer are forced to move downward by the wind, causing all four capacitances $\left(C_{1}, C_{2}, C_{3}\right.$ and $\left.C_{4}\right)$ to increase. Obviously, the higher the wind speed, the greater the capacitances change.

Therefore, the wind sensor can transform the 2.5D wind field information into easily measurable capacitance information. The wind direction is characterized by the change in trend of capacitance and the wind speed is characterized by the change magnitude of capacitance.

\subsection{Simulation by FEM}

In order to verify the feasibility of the proposed sensor, simulations were performed using the finite element method (FEM) solver (COMSOL 5.5). The $x$ and $y$ axes were equivalent due to the rotational symmetry of the sensor in the xy-plane. Therefore, the simulation variables included the wind speed in the xy-plane, the wind direction in the $x y$-plane, and the wind speed in the $z$-axis. The results of the simulations showed the change in the distance between the upper and lower electrodes, which characterized the deformation of the device and determined the change in four differential capacitances. Figure 3 shows the simulation results when the wind direction was fixed at $0^{\circ}$ and the wind speed was changed from $0 \mathrm{~m} / \mathrm{s}$ to $25 \mathrm{~m} / \mathrm{s}$ in the xy-plane. Obviously, as the wind speed 
increased, the distances $\left(d_{1}\right.$ and $\left.d_{2}\right)$ on the windward side increased and the distances $\left(d_{3}\right.$ and $\mathrm{d}_{4}$ ) on the leeward side decreased. Figure 4 shows the simulation results when the wind speed was fixed at $12.7 \mathrm{~m} / \mathrm{s}$ and the wind direction was changed from $0^{\circ}$ to $360^{\circ}$ in the xy-plane. The distances between plates changed as a sine function to the wind direction.

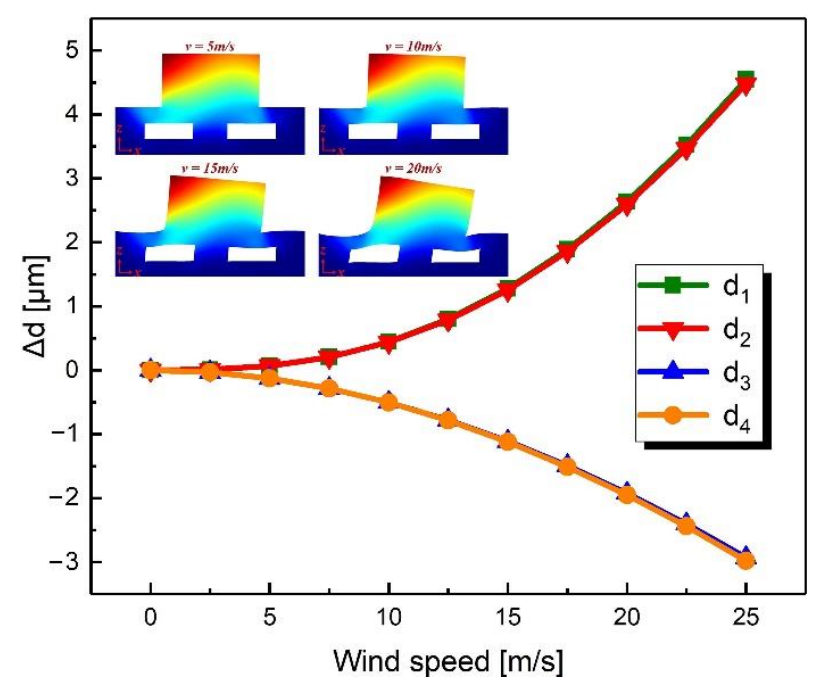

Figure 3. Simulated change in gap distances when the wind speed varied from $0 \mathrm{~m} / \mathrm{s}$ to $25 \mathrm{~m} / \mathrm{s}$ in the xy-plane with a fixed direction of $0^{\circ}$.

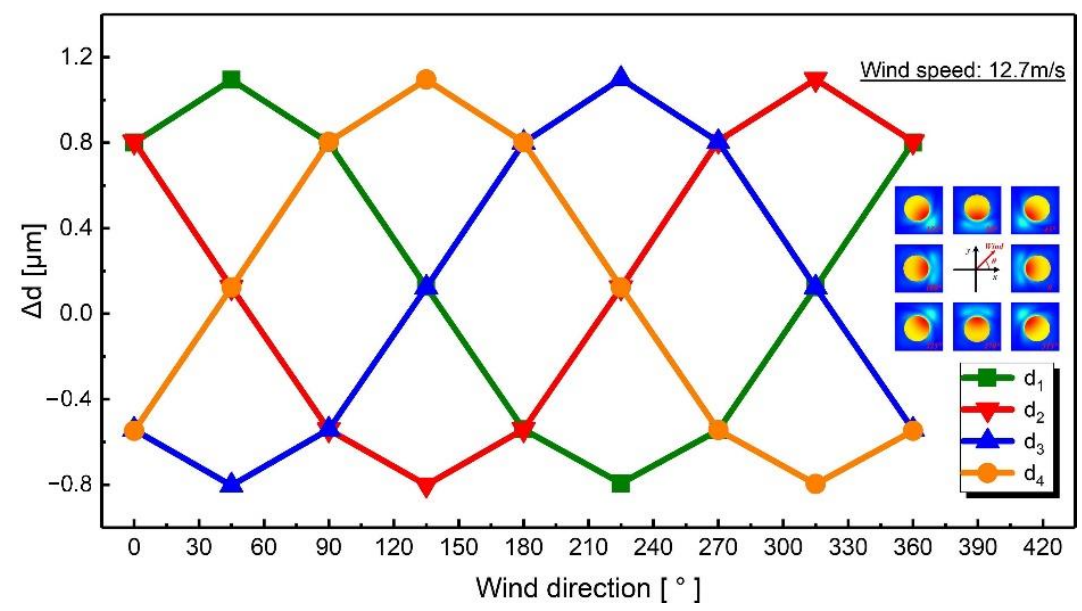

Figure 4. Simulated change in gap distance when the wind direction changed from $0^{\circ}$ to $360^{\circ}$ in the xy-plane with a fixed wind speed of $12.7 \mathrm{~m} / \mathrm{s}$.

Figure 5 shows the simulation results when the wind speed was changed from 0 to $25 \mathrm{~m} / \mathrm{s}$ in the $z$-axis. All distances decreased as the wind speed increased. The above simulation results are consistent with expectations. Moreover, it should be noted that at the same wind speed in the xy-plane the change in distance on the windward side was greater than that on the leeward side, which indicated that the deformation of the device caused by the tilt of the windward pillar was asymmetrical. 


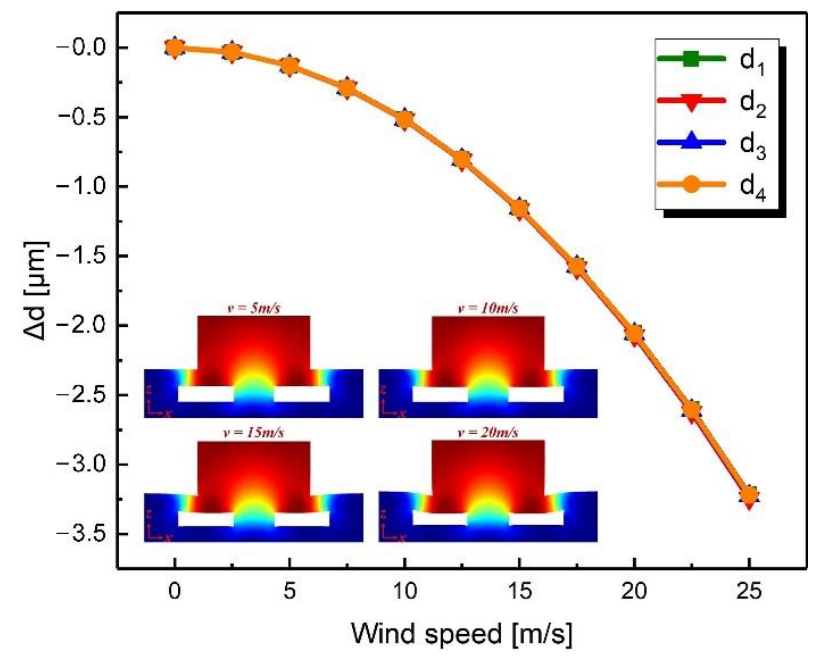

Figure 5. Simulated change in gap distance when the wind speed changed from $0 \mathrm{~m} / \mathrm{s}$ to $25 \mathrm{~m} / \mathrm{s}$ in the $z$-axis.

\section{Fabrication}

\subsection{Material Selection}

According to the operation principle, the material of the proposed flexible sensor should meet the special requirements. Firstly, the material should have plasticity to form a specific device structure. Secondly, the material should have a controllable Young's modulus. The windward pillar and the support layer should have a large Young's modulus to maintain the basic structure of the sensor, while the upper and lower electrode layers should have a small Young's modulus to improve the sensitivity of the sensor. Thirdly, the material should have good adhesion with the metal to facilitate the preparation of the electrodes. Finally, the material should meet the bonding requirements so that all layers can bond together to form a complete device.

Based on the above considerations, PDMS was the most promising substrate material to fabricate the device. PDMS is prepared by mixing and curing the matrix and curing agent. Generally, the mass ratio of the matrix and curing agent has an influence on the Young's modulus of the solidified PDMS. Table 2 shows the Young's modulus of PDMS with different mass ratios [20], in which it can be seen that the higher the mass ratio is, the lower the Young's modulus is. Therefore, the Young's modulus of PDMS can be controlled by adjusting the mass ratio to meet the needs of different structural layers.

Table 2. Young's modulus of solidified PDMS with different mass ratios.

\begin{tabular}{cc}
\hline Mass Ratio & Young's Modulus [MPa] \\
\hline $8: 1$ & $2.15 \pm 0.02$ \\
$10: 1$ & $1.97 \pm 0.03$ \\
$12: 1$ & $1.62 \pm 0.02$ \\
$15: 1$ & $1.25 \pm 0.03$ \\
\hline
\end{tabular}

In addition, copper was chosen as the electrode material due to its good electrical conductivity, mature preparation technology, and low cost.

\subsection{Fabrication Process}

The fabrication process of the proposed wind sensor is illustrated in Figure 6. Firstly, four molds corresponding to the structure layers were made using 3D printing technology. The matrix and curing agents of PDMS were then mixed in a mass ratio of 10:1 and 20:1. Subsequently, the former was poured into the mold corresponding to the windward pillar and the supporting layer, while the latter was poured into the mold corresponding to the 
upper and lower electrode layers. The PDMS and the mold were cured at a temperature of $90{ }^{\circ} \mathrm{C}$ for about $4 \mathrm{~h}$. After that, the four structural layers were peeled from the mold. Next, copper was sputtered on the upper and lower electrode layers using magnetron sputtering technology, one of the physical vapor depositions (PVDs), to form the electrodes. Finally, the four structural layers were assembled into a complete device using plasma bonding technology.

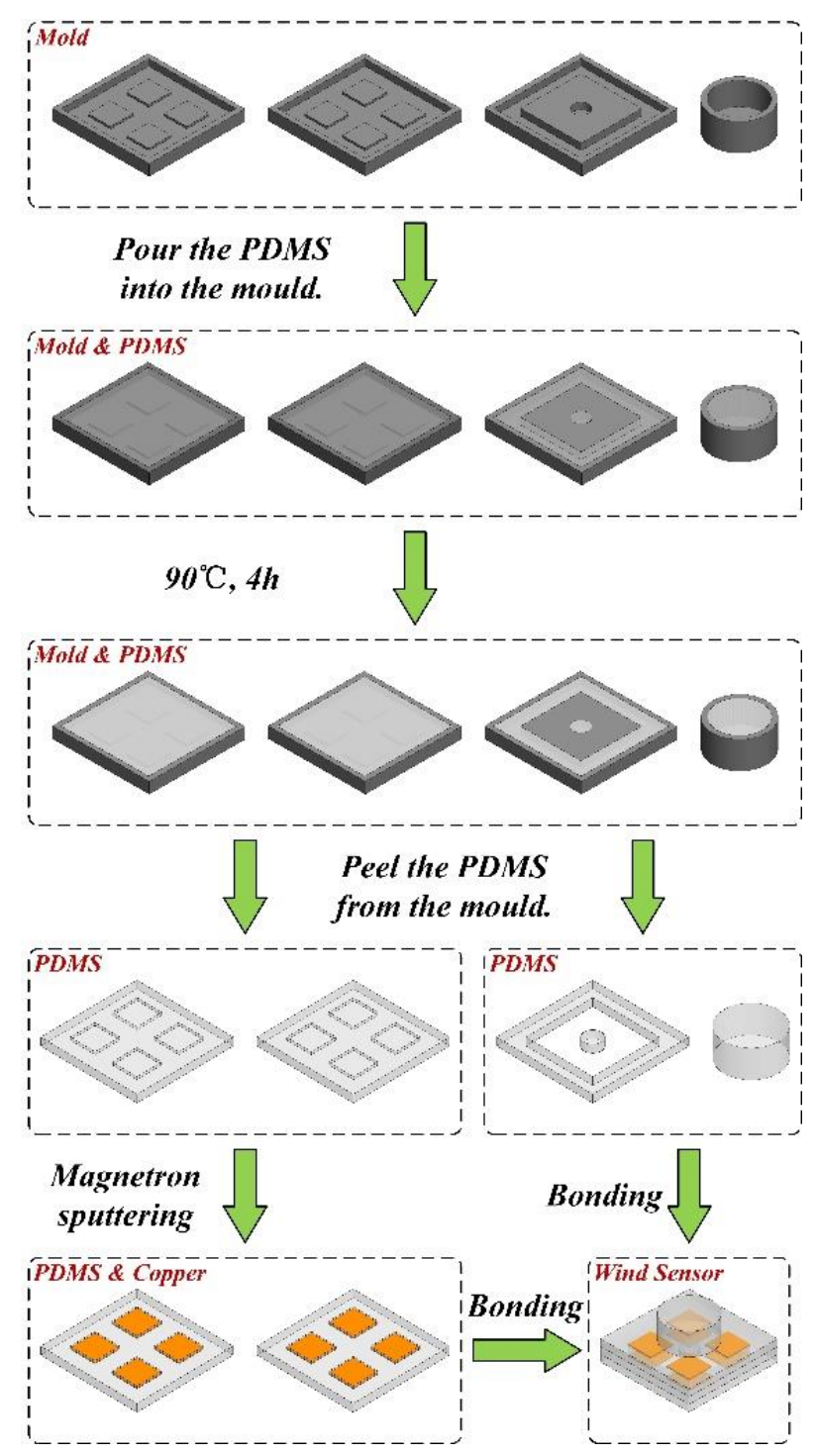

Figure 6. Fabrication process of the proposed flexible wind sensor.

Photographs of the fabricated wind sensor, as well as each layer, are shown in Figure 7. The dimensions of the sensor are close to $40 \mathrm{~mm} \times 40 \mathrm{~mm} \times 19 \mathrm{~mm}$. Due to errors in the fabrication process, such as nonuniform gaps between copper electrodes, the four capacitors $\left(C_{1}, C_{2}, C_{3}\right.$ and $\left.C_{4}\right)$ show different initial capacitances without external force, which are measured to be about 1.099, 1.085, 1.113, and $1.105 \mathrm{pF}$, respectively. 

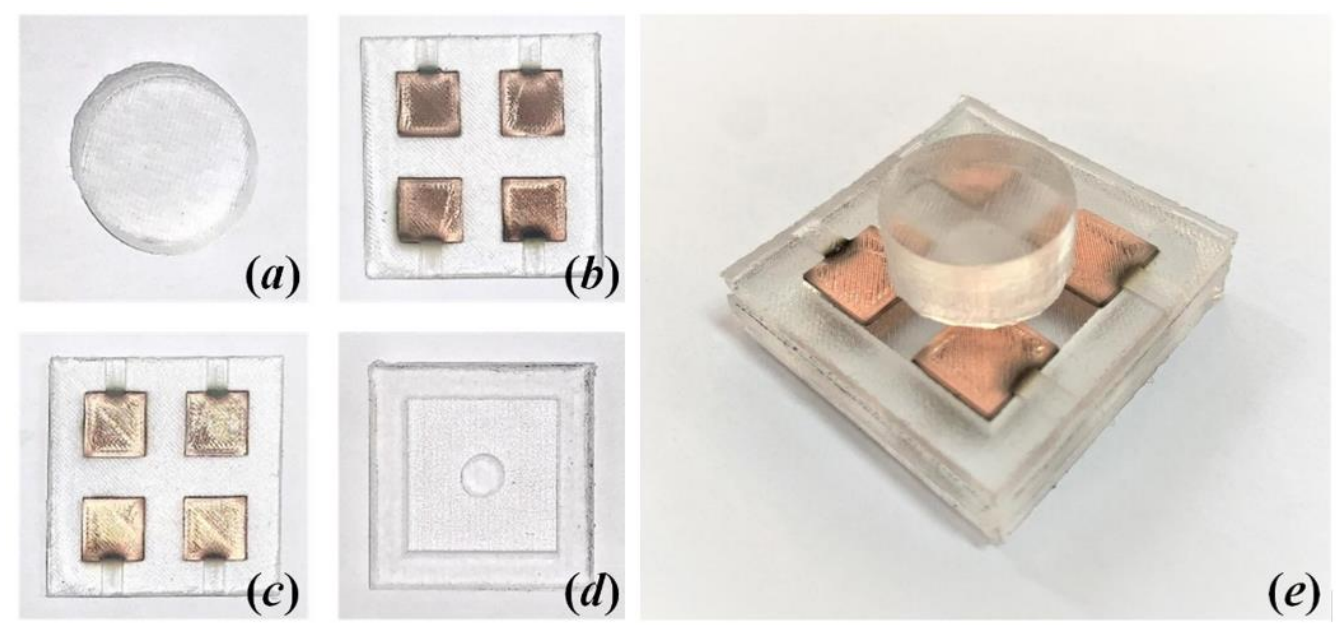

Figure 7. Photographs of (a) the windward pillar, (b) the upper electrode layer, (c) the support layer, (d) the lower electrode layer, and (e) the fabricated wind sensor.

\section{Measurements}

The setup for wind speed and direction measurement is shown in Figure 8 and it includes three parts: the wind speed experiments in the xy-plane, the wind direction experiments in the xy-plane, and the wind speed experiments in the $z$-axis. The sensor is fixed on the bracket placed in the wind tunnel. The wind speed is controlled by adjusting the fan speed, while the wind direction is controlled by rotating the bracket. The capacitances of the four capacitors are measured using an AD7747 evaluation board. In order to minimize errors in the measurements, the average value from 100 measurements was taken for every data point. In addition, since the initial capacitances of the four capacitors were different, the measured capacitances were not conducive to analysis and comparison. Therefore, it was necessary to normalize them (minus the initial capacitance) to get the capacitance change magnitude as the dependent variable of wind speed and direction.

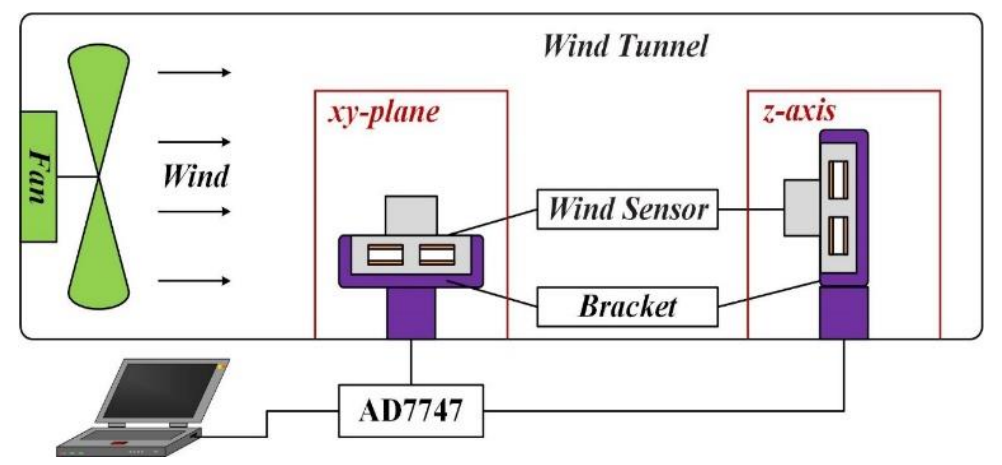

Figure 8. The setup for wind speed and direction measurement.

\subsection{Wind Speed Experiments in $x y$-Plane}

For these measurements, the wind direction was fixed at $0^{\circ}$ (the direction of $x$-axis) and the wind speed was changed from $0 \mathrm{~m} / \mathrm{s}$ to $23.9 \mathrm{~m} / \mathrm{s}$. Figure 9 shows the recorded capacitance change magnitudes as they changed with the wind speed. When the wind speed was between $0 \mathrm{~m} / \mathrm{s}$ and $6.4 \mathrm{~m} / \mathrm{s}$, the capacitance did not change significantly (no more than $1 \mathrm{fF} \cdot \mathrm{m}^{-1} \cdot \mathrm{s}$ ). When the wind speed was greater than $6.4 \mathrm{~m} / \mathrm{s}$, the wind would cause the effective deformation of the device. As the wind speed increased, $C_{1}$ and $C_{2}$ decreased while $C_{3}$ and $C_{4}$ increased, which was consistent with expectations. The maximum variation of capacitance was about $0.058 \mathrm{pF}$ at a wind speed of $23.9 \mathrm{~m} / \mathrm{s}$, and the sensitivity of the device was $4 \mathrm{fF} \cdot \mathrm{m}^{-1} \cdot \mathrm{s}$. 


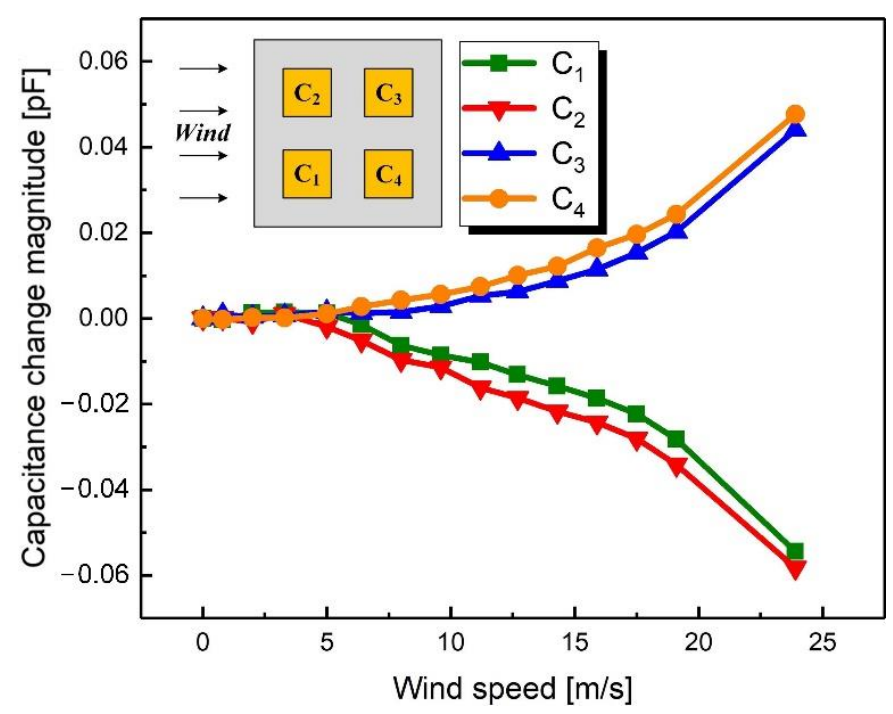

Figure 9. Measured capacitance change magnitudes when the wind speed varied from $0 \mathrm{~m} / \mathrm{s}$ to 23.9 $\mathrm{m} / \mathrm{s}$ with a fixed wind direction of $0^{\circ}$.

\subsection{Wind Direction Experiments in $x y$-Plane}

For these measurements, the capacitance change magnitudes are shown in Figure 10, when the wind direction was changed from $0^{\circ}$ to $360^{\circ}$ with a fixed wind speed of $12.7 \mathrm{~m} / \mathrm{s}$. It can be deduced from the scatter diagram that the change trend of capacitances was similar to the trigonometric function, which is consistent with the simulations. Therefore, the sine function $(\mathrm{y}=\mathrm{y} 0+A \sin [\omega(\mathrm{x}-\varphi)])$ is applied to fit the measured data, and the fitting results are shown in Table 3 . The phase difference of adjacent capacitance change curves is about $90^{\circ}$. The extreme points of the capacitance change curves are $45^{\circ}, 135^{\circ}$, $225^{\circ}$, and $315^{\circ}$, which were the diagonal directions of the device. The maximum variation of capacitance was up to $0.025 \mathrm{pF}$.

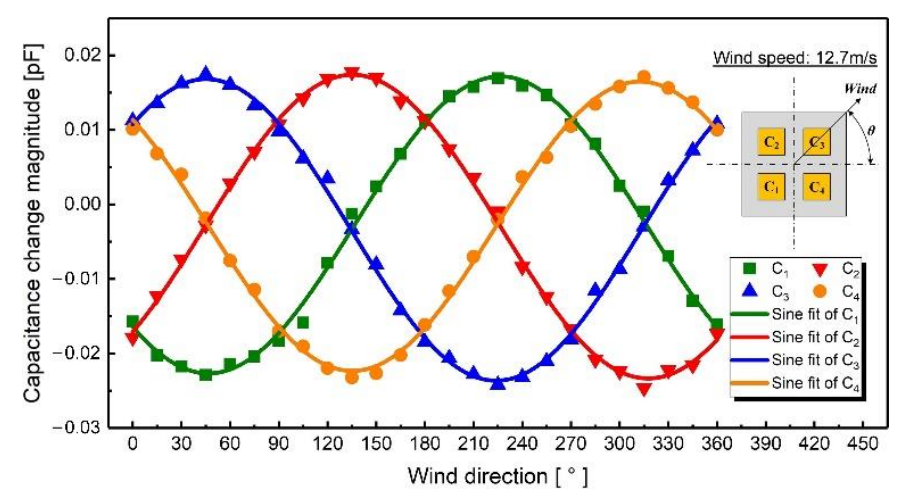

Figure 10. Measured capacitance normalized by the initial value when the wind speed was fixed at $12.7 \mathrm{~m} / \mathrm{s}$ and the wind direction was changed from $0^{\circ}$ to $360^{\circ}$.

Table 3. Fitting results of the measured capacitance change magnitude.

\begin{tabular}{ccccc}
\hline Parameters & $\mathbf{C}_{\mathbf{1}}$ & $\mathbf{C}_{\mathbf{2}}$ & $\mathbf{C}_{\mathbf{3}}$ & $\mathbf{C}_{\mathbf{4}}$ \\
\hline $\mathrm{y}_{0}$ & -0.00276 & -0.00298 & -0.00342 & -0.00293 \\
$\mathrm{~A}$ & 0.01993 & 0.02038 & 0.02024 & 0.01942 \\
$\omega$ & 1.00065 & 0.98817 & 1.00662 & 1.01593 \\
$\varphi$ & 136.6596 & 44.39655 & -44.23719 & -136.10507 \\
\hline
\end{tabular}




\subsection{Wind Speed Experiments in $z$-Axis}

For these measurements, the wind direction was fixed at the direction of the negative $z$-axis while the wind speed was changed from $0 \mathrm{~m} / \mathrm{s}$ to $23.9 \mathrm{~m} / \mathrm{s}$. Figure 11 shows the relationship between the capacitance change magnitudes and the wind speed. It can be observed that when the wind speed was less than $9.6 \mathrm{~m} / \mathrm{s}$, the capacitance did not change significantly. When the wind speed was greater than $9.6 \mathrm{~m} / \mathrm{s}$, all four capacitances $\left(C_{1}\right.$, $\mathrm{C}_{2}, \mathrm{C}_{3}$ and $\mathrm{C}_{4}$ ) increased with the wind speed, which is consistent with expectations. The maximum variation of capacitance was $0.041 \mathrm{pF}$ for the wind speed of $23.9 \mathrm{~m} / \mathrm{s}$ and the sensitivity of the device was in the order of $3 \mathrm{fF} \cdot \mathrm{m}^{-1} \cdot \mathrm{s}$.

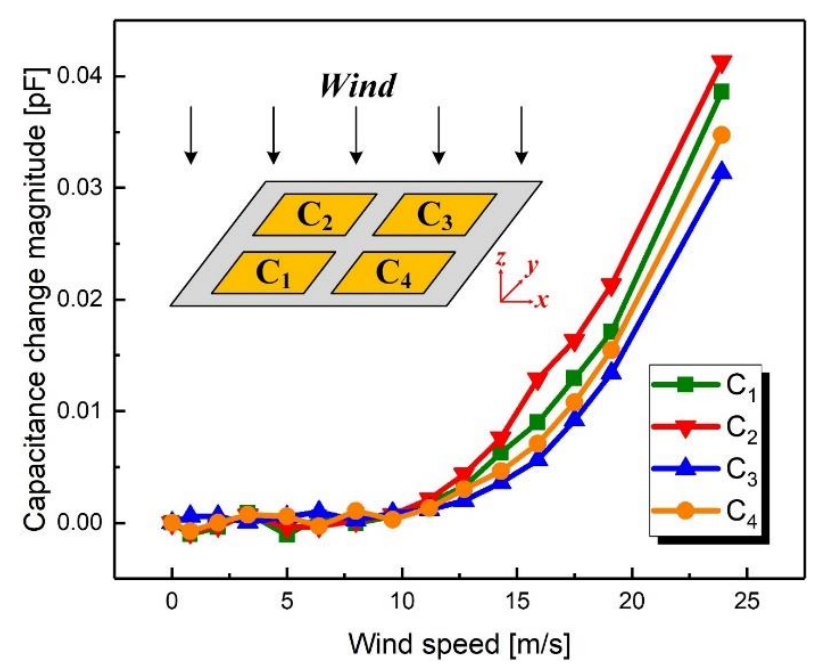

Figure 11. Measured capacitance change magnitudes when the speed was changed from $0 \mathrm{~m} / \mathrm{s}$ to $23.9 \mathrm{~m} / \mathrm{s}$ for the wind blowing from the positive $z$-axis to the negative $z$-axis.

\section{Discussion}

As shown in Figures 9 and 11, the capacitances are not sensitive to the wind at low speeds. The reason is that the stress caused by the wind is proportional to the square of the speed. Therefore, at low wind speeds, the stress is too small to produce the deformation that can cause a change in capacitance. There are several solutions to improve the sensitivity of the device. On the one hand, the windward area of the device can be enlarged by increasing the height of the windward pillar so that the device is subjected to greater stress for the same wind speed. On the other hand, the Young's modulus of the device may be reduced by increasing the proportion of the matrix in the PDMS so that the device undergoes greater deformation under the same stress. Additionally, trenches designed in the upper electrode layer can also change the gap distance to achieve improved sensitivity at low wind speeds. The maximum detectable wind speed is also higher than $23.9 \mathrm{~m} / \mathrm{s}$, but this was the limit of the wind tunnel used in this paper.

Moreover, the capacitance changes observed were inconsistent with the simulation results, which means that there were errors in the measurement results. First of all, the fringing field capacitance was not considered in the theoretical analysis. Secondly, the thickness of the structure layers was not uniform and the surface of the electrodes was uneven, leading to the differences in the performance of the four capacitors. Thirdly, the capacitance measurement results included the interference in the environment, which made the capacitance fluctuate. Finally, due to manual assembly, the center of the windward pillar was not strictly aligned with the center of the electrode layer, resulting in errors in the measurement results of the wind direction.

It should be noted that the proposed sensor cannot measure the speed for the wind from the negative direction of the $z$-axis. In order to remedy this defect, two 2.5D wind sensors could be superimposed to achieve the measurement of 3D wind. 


\section{Conclusions}

In this paper, a novel flexible 2.5D wind sensor based on differential plate capacitors has been designed, simulated, fabricated, and characterized. The wind sensor can transform the 2.5D wind field information into capacitance information, where the wind direction is characterized by the change trend of capacitances and the wind speed is characterized by the change magnitude of capacitances. Moreover, the electrodes of the capacitors can be embedded in the substrate to avoid interference from the external environment, which would improve the reliability of the device. Experimental results demonstrate that the sensor can determine the wind direction over the full range of $360^{\circ}$ in the xy-plane, and the sensitivities to wind speed are $4 \mathrm{fF} \cdot \mathrm{m}^{-1} \cdot \mathrm{s}$ and $3 \mathrm{fF} \cdot \mathrm{m}^{-1} \cdot \mathrm{s}$ in the xy-plane and $z$-axis, respectively. The proposed flexible wind sensor exhibits some potential in areas that require devices with low power consumption and high reliability.

Author Contributions: Conceptualization, Y.W. and Z.Y.; methodology, Y.W.; software, Y.W.; validation, Y.W. and Z.Y.; formal analysis, Y.W.; investigation, Y.W.; resources, Z.Y.; data curation, Y.W.; writing-original draft preparation, Y.W.; writing—review and editing, Z.Y.; visualization, Y.W.; supervision, Z.Y.; project administration, Z.Y.; funding acquisition, Z.Y. All authors have read and agreed to the published version of the manuscript.

Funding: This research was funded by the National Natural Science Foundation of China (grant number 6506000174), and Zhishan Scholar Program of Southeast University in China. This research is also a part of the National Key Research and Development Program of China (Grant number 2018YFF01010600).

Institutional Review Board Statement: Not applicable.

Informed Consent Statement: Not applicable.

Data Availability Statement: The data presented in this study are available on request from the corresponding author.

Conflicts of Interest: The authors declare no conflict of interest.

\section{References}

1. Suomi, I.; Vihma, T. Wind Gust Measurement Techniques-From Traditional Anemometry to New Possibilities. Sensors 2018, 18, 1300. [CrossRef] [PubMed]

2. van Putten AF, P.; Middelhoek, S. Integrated silicon anemometer. Electron. Lett. 1974, 10, 425-426. [CrossRef]

3. Stemme, G. A CMOS integrated silicon gas-flow sensor with pulse-modulated output. Sens. Actuators 1988, 14, 293-303. [CrossRef]

4. Zhu, Y.; Chen, B.; Qin, M.; Huang, Q.-A. 2-D micromachined thermal wind sensors-A review. IEEE Internet Things J. 2014, 1, 216-232. [CrossRef]

5. Moser, D.; Lenggenhager, R.; Wachutka, G.; Baltes, H. Fabrication and modelling of CMOS microbridge gas-flow sensors. Sens. Actuators B Chem. 1992, 6, 165-169. [CrossRef]

6. Neda, T.; Nakamura, K.; Takumi, T. A polysilicon flow sensor for gas flow meters. Sens. Actuator A Phys. 1996, 54, 626-631. [CrossRef]

7. Hung, S.-T.; Wong, S.-C.; Fang, W. The development and application of microthermal sensors with a mesh-membrane supporting structure. Sens. Actuators A Phys. 2000, 84, 70-75. [CrossRef]

8. Wang, S.; Yi, Z.; Qin, M.; Huang, Q.-A. Modeling, simulation, and fabrication of a 2-D anemometer based on a temperaturebalanced mode. IEEE Sens. J. 2019, 19, 4796-4803. [CrossRef]

9. Ye, Y.; Yi, Z.; Gao, S.; Qin, M.; Huang, Q.-A. Effect of insulation trenches on micromachined silicon thermal wind sensors. IEEE Sens. J. 2017, 17, 8324-8331. [CrossRef]

10. Kim, Y.-M.; Seo, C.-T.; Eun, D.-S.; Park, S.-G.; Jo, C.-S.; Lee, J.-H. Characteristics of cantilever beam fabricated by silicon micromachining for flow sensor application. In Proceedings of the Sensors 2003 IEEE, Toronto, ON, Canada, 22-24 October 2003; pp. 642-646.

11. Wang, Q.; Wang, Y.; Dong, L. MEMS flow sensor using suspended graphene diaphragm with microhole arrays. J. Microelectromech. Syst. 2018, 27, 951-953. [CrossRef]

12. Tan, Y.K.; Panda, S.K. A novel piezoelectric based wind energy harvester for low-power autonomous wind speed sensor In Proceedings of the IECON 2007-33rd Annual Conference of the IEEE Industrial Electronics Society, Taipei, Taiwan, 5-8 November 2007; pp. 2175-2180. 
13. Liu, H.; Zhang, S.; Kathiresan, R.; Kobayashi, T.; Lee, C. Development of piezoelectric microcantilever flow sensor with wind-driven energy harvesting capability. Appl. Phys. Lett. 2012, 100, 223905. [CrossRef]

14. Bruschi, P.; Dei, M.; Piotto, M. A Low-Power 2-D Wind Sensor Based on Integrated Flow Meters. IEEE Sens. J. 2009, 9, 1688-1696. [CrossRef]

15. Kessler, Y.; Ilic, B.R.; Krylov, S.; Liberzon, A. Flow sensor based on the snap-through detection of a curved micromechanical beam. J. Microelectromech. Syst. 2018, 27, 945-947. [CrossRef] [PubMed]

16. Yi, Z.; Wan, Y.; Qin, M.; Huang, Q. Novel anemometer based on inductor bending effect. J. Microelectromech. Syst. 2019, 28, 321-323. [CrossRef]

17. Yi, Z.; Wan, Y.; Qin, M.; Huang, Q. Quadruple sensitivity improvement for wind speed sensor using dual-layer bended inductors. Sens. Actuator A Phys. 2020, 303, 1-4. [CrossRef]

18. Park, S.; Kim, H.; Vosgueritchian, M.; Cheon, S.; Koo, J.H.; Kim, T.R.; Lee, S.; Schwartz, G.; Chang, H. Stretchable EnergyHarvesting Tactile Electronic Skin Capable of Differentiating Multiple Mechanical Stimuli Modes. Adv. Mater. 2014, 43, 7324-7332. [CrossRef] [PubMed]

19. Park, S.; Park, J.; Kim, Y.; Bae, S.; Kim, T.-W.; Park, K.-I.; Hong, B.H.; Jeong, C.K.; Lee, S.-K. Laser-directed synthesis of strain-induced crumpled MoS2 structure for enhanced triboelectrification toward haptic sensors. Nano Energy 2020, 78, 105266. [CrossRef]

20. Lai, H.; Yuan, C.; Lin, H. Camber deformation property and fracture strain of flexible film made by polydimethylsiloxane. Opt. Mater. 2020, 107, 110066. [CrossRef] 